\title{
PRESERVATION AND RESTORATION OF A PIECE OF TEXTILE AT THE EGYPTIAN TEXTILE MUSEUM
}

\author{
Amin, E. ${ }^{1} \&$ Rashed, S. ${ }^{2}$ \\ ${ }^{1}$ Lecturer Conservation dept., Faculty of Fine Arts, Minia Univ., Minia, Egypt \\ ${ }^{2}$ Manager of Conservation Department, Egyptian Textile Museum, Egypt \\ E-mail: enas.mohamed_17@yahoo.com
}

\begin{abstract}
The research includes a treatment and restoration of a piece of textile from the Abbasid period which decorated with writing. It was stored in the Egyptian Textile Museum. The piece has been found in a severe damage case that led to the weak fibers. It has many missing areas, stains and dirt. Scanning electron microscopy was used to analyze the fibers to identify them and to characterize their deterioration. UV Analysis was used to identify the type of dye and identify the type of adhesive which the piece pasted with it on a free acid paper. The piece was treated by supporting it by using needle work. Finally the piece was prepared for museum display.
\end{abstract}

Keywords: Treatment, Textile, Abbasid period, Weak fibers, Needle work.

\section{Introduction}

This piece was chosen for treatment because among the wide range of objects of cultural heritage, textiles are the most fragile and less preserved. Most of them did not survive over time because of the poor preservation conditions. The fragility of textiles can be directly related to the fact that they are composed of mainly, if not completely, organic material [1]. The piece was made of linen which composed of cellulose. The cellulose is a semi-crystalline biopolymer, naturally synthesized as nanofibrils [2]. The main interactions acting on the structure of cellulose and causing its alteration and aging are photo-degradation, acid hydrolysis, oxidation, biodegradation
[3]. The sources of aging include chemical tendering, thermal aging high temperatures, light aging [4] [5] and moisture plays a major role in degradation chemistry that degradation will be speeded up by the presence of moisture [6]. A complete analysis of them is quite complex, since these phenomena are all related to each other. In order to a better understanding of the reactions related to the natural oxidative aging of the textiles. The oxidation reactions of cellulose involve the primary and secondary hydroxyl groups of the pyranose ring and result in carbonyl and carboxyl groups. This reaction can be accompanied by the opening the pyranose ring. In any cases 
the glucosidic bond becomes weaker; the formation of carboxyl groups induces a de-polymerization, thus reducing the polymerization degree (DP) and the physical and mechanical strength of the material. The compound result is the di-aldehyde cellulose (DAC) [3]. Aging of textiles can cause drastic visual changes [7] and heavily affects the appearance and mechanical properties [8]. As fibers reach the micro-crystalline level, the change rate in molecular and chemical properties, such as $\mathrm{DP}^{-}$or carbonyl level, slows down considerably [9]. The fibers are become so brittle that it is necessary to apply consolidation procedures. In order to better apply consolidation the deep study based on findings specific analysis was applied [10]. Ease of reversibility of the consolidation is an issue with textiles to remove it at any

\subsection{Description and conditions}

The piece of linen is dated back to the Abbasid period, fig. (1) 9 A.D. century, 3 A.H. The number of registry is 606. There are writings in horizontal line in mid-piece woven in dark yellow color with $1 \mathrm{~cm}$ thickness reads, figs. (2-a, b, c). It has been found in the excavations and saved in Egyptian Textile Museum. The textile structure of the pieces is plain 1/1. Plain weave is the simplest of all weaves. It has one-over one-under interlacing for both warp and filling yarns [14], and match here warp thread color with the color of weft yarn but in the place of written units the piece has been weaved with the technique of Weft - Face Textile with technical of systematic extending plain weave from warp 2/2. A figurative weft-faced textile woven by hand on a loom [15] which occurs where the decoration through the use of all colorful weave the woven weft does not reach from the side to the other side but it is woven only in the space for decoration, the results the presence of vertical slits and small holes, fig. (3) at the vertical borders of the words as a result of using reflection discolored time without damaging the fibers [11]. The consolidation must remain stable long enough so that the "useful lifetime" of the object will be substantially prolonged [12]. The consolidation was made by supporting this object by needle work on a textile support. The most effective support of a weak textile is to line it with a suitable fabric. This step includes laying the object on a suitable mounting fabric [13]. The main purpose of the present paper is treatment this piece of Islamic textile with support it on a textile support with needle work to improve its properties by slowing down the rate of further deterioration. This type of consolidate is to be fulfilled the reversibility and stable long enough. After making these supports, the piece was prepared for the museum display.

wefts to dark yellow [16]. Warp yarns are 30 and yarns of weft are 22 by square centimeter. The Argatch was not found. The object has been tattered and a severe dry state in the terminal fringes because the piece has been adhered on a free acid paper with adhesive material at the excavations site. The beginning and the end of the words on the written tape aren't completed. The piece has already been cleaned at the excavation site and moistened with water and then put it on a free acid paper with an adhesive with the restoration of part of it with needle work (with running stitch), fig. (4). It shows many types of damage, fig $_{\text {s. }}(5-\mathrm{a}, \mathrm{b}, \mathrm{c}, \mathrm{d}, \mathrm{e}, \mathrm{f}, \mathrm{g})$ including weakness of fibers, many missing parts, dry, and dark brown spot at the left bottom of the widget and its fibers stiff and too weak. In addition to the weakness of yellow weft threads used in weaving the writing, it breaks and falls. There is also freelancer spotted result of moistened the piece with water during glued it on a free acid paper and it led to the spread of weak dye. The piece size is: $13 \times 30.5 \mathrm{~cm}$. 


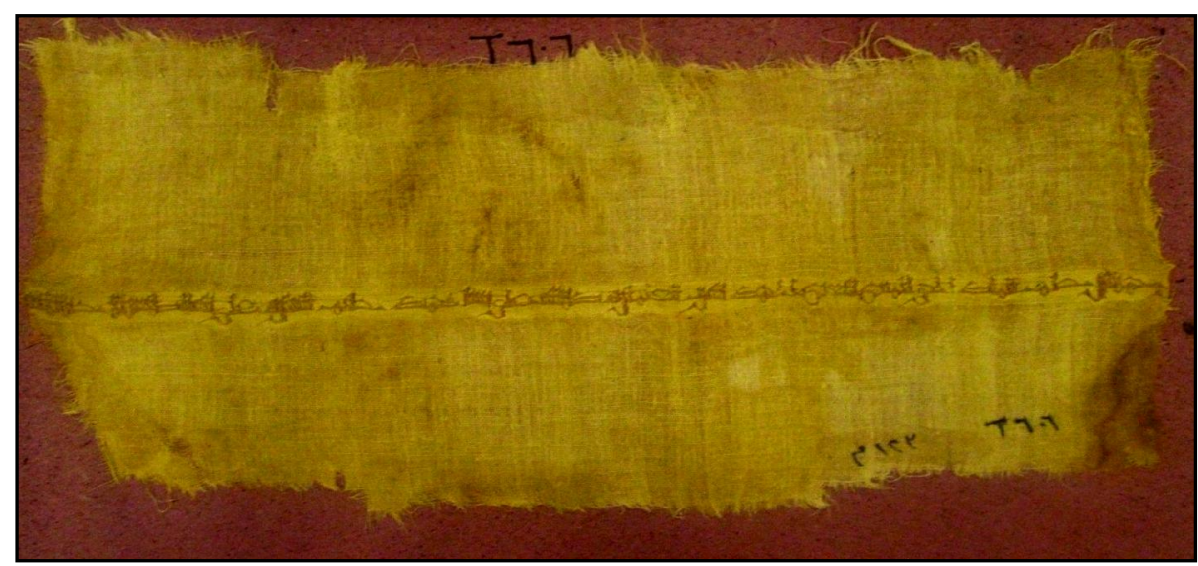

Figure (1) Piece dates back to the Abbasid period, size is: $13 \times 30.5 \mathrm{~cm}$ contain "El Rahman, El Rahim, the king, the right, the certainty, praise be to Allah the lord of the worlds, and may Allah bless on our Prophet Muhammad which is the seal of the Prophets, and on a good people whose they good guys and Alatakih.”

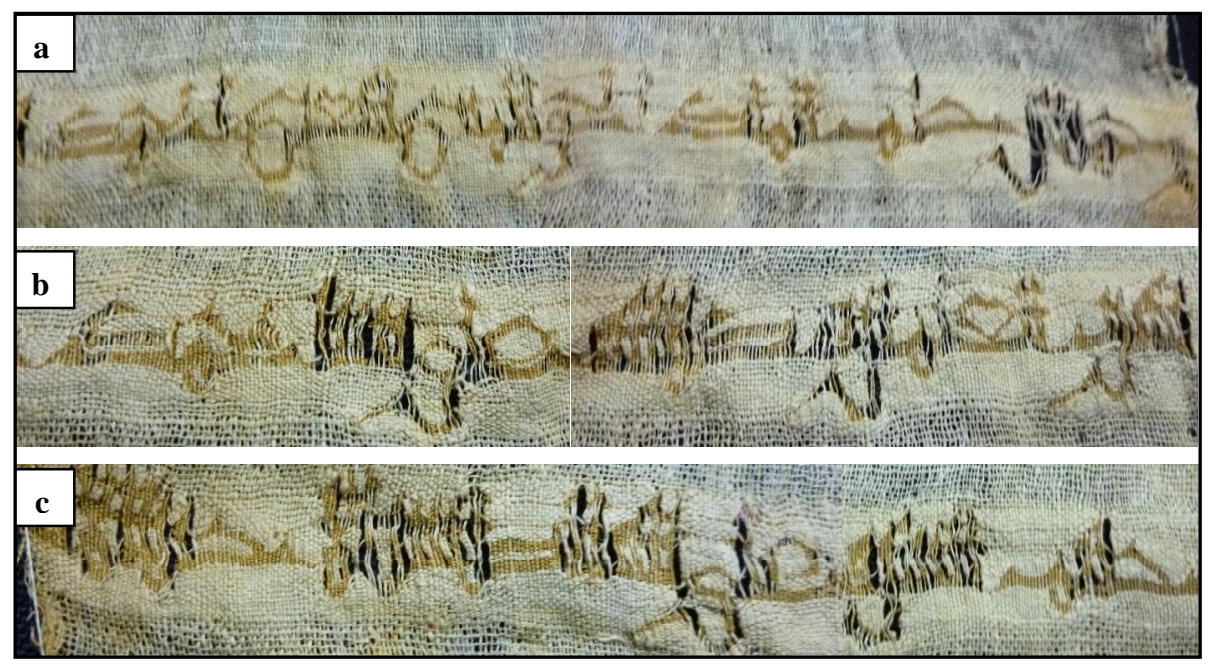

Figure (2) Writings reads contain a El Rahman, El Rahim, The king, the right, the certainty, Praise be to, $\underline{\mathbf{b}}$ Allah the lord of the worlds, and may Allah bless on our Prophet Muhammad, $\underline{\mathbf{c}}$ Which is the seal of the Prophets, and on a good people whose they good guys and Alatakih.

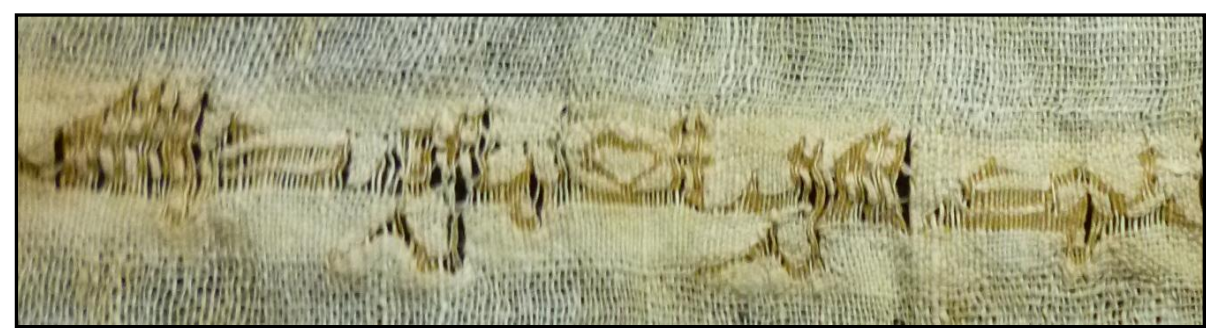

Figure (3) Presence of vertical slits and small holes at the vertical borders of the words

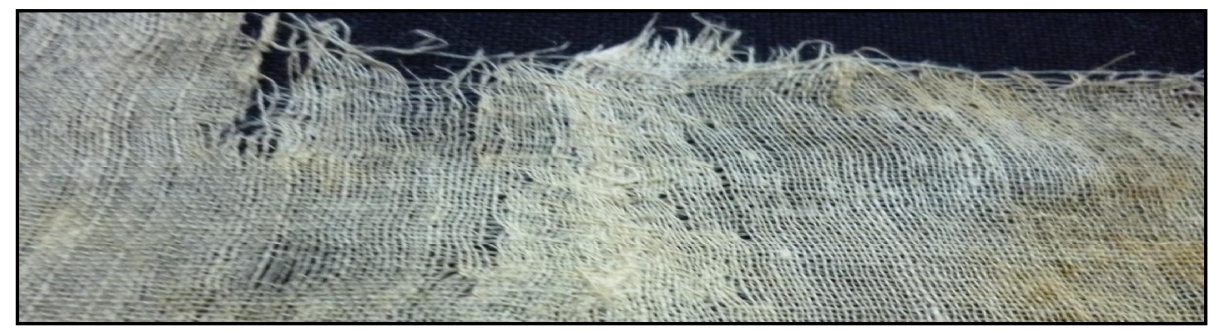

Figure (4) A restored part of the piece with running stitch 


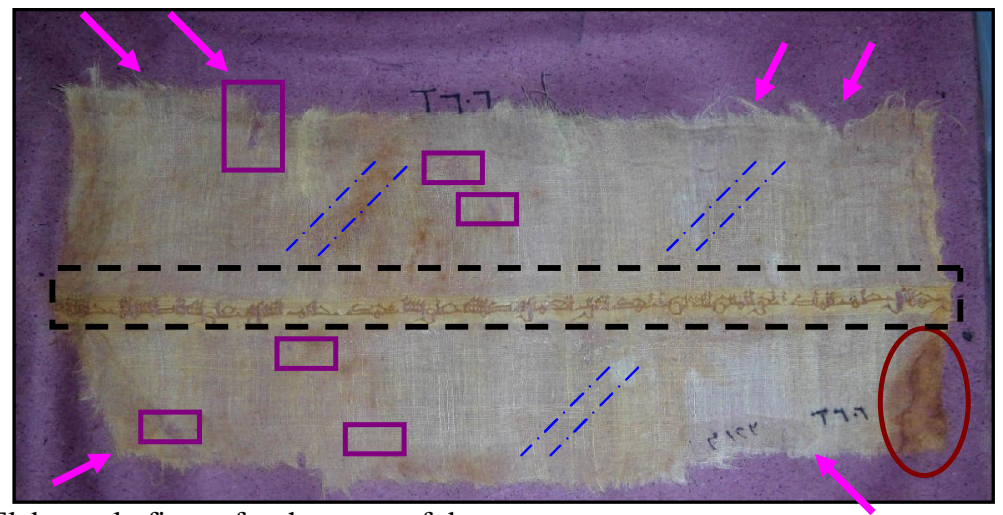

Figure (4-a) Elaborately figure for the types of damage
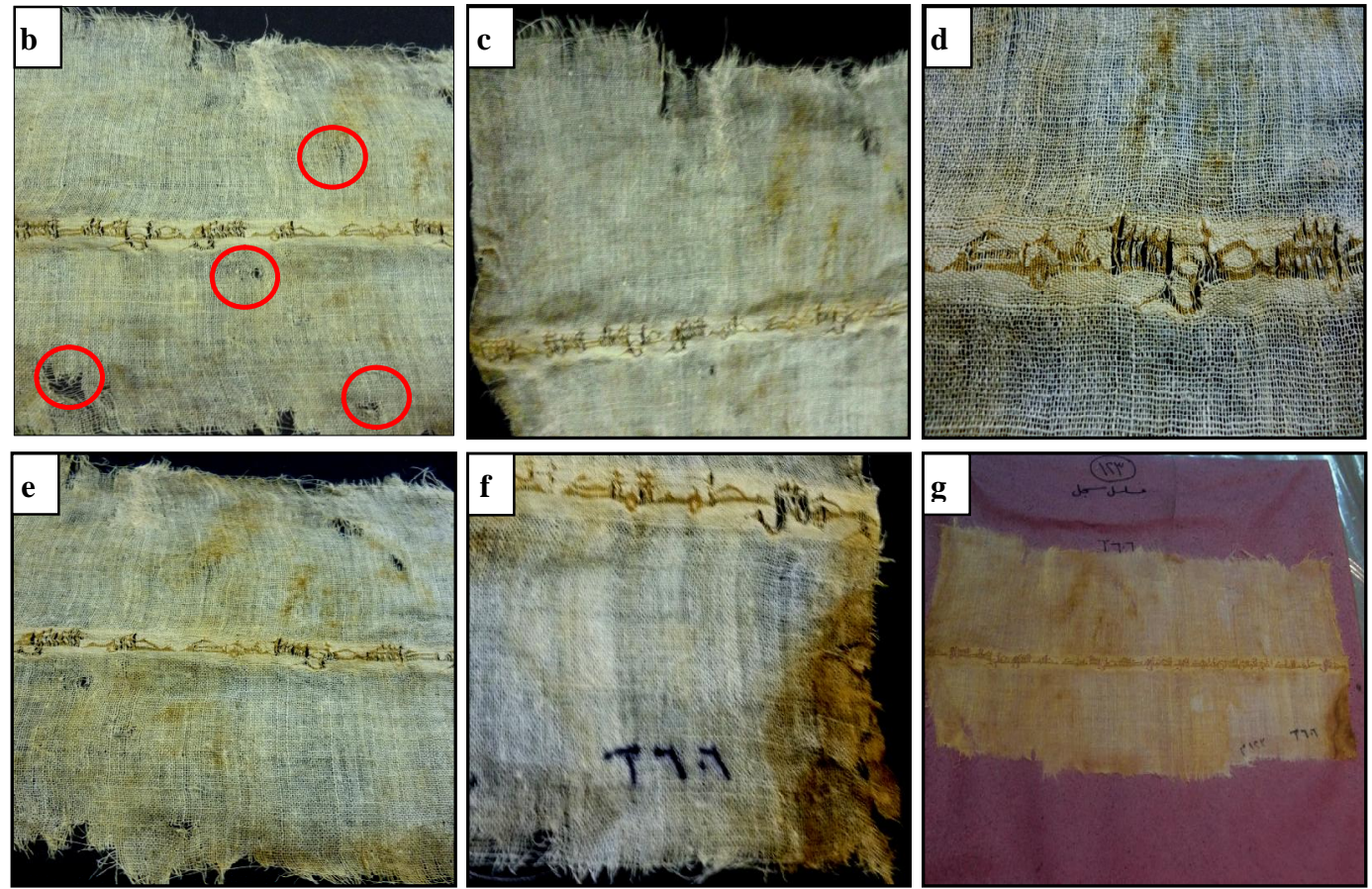

Figure (5) $\underline{\mathbf{b}}$ Missing parts in the piece $\underline{\mathbf{c}}$ many missing parts in the piece, $\underline{\mathbf{d}}$ weakness of yellow weft threads, $\underline{\mathbf{e}}$ freelancer spotted, $\underline{\mathbf{f}}$ dark brown spot at the left bottom of the piece, $\mathbf{g}$ the piece adhered on a free acid paper with adhesive material at the excavations site

\section{Examination and Analysis Methods}

Scanning Electron Microscope is used for studying the morphological features of the archaeological materials. It allows us to detect different microscopic features of the natural fiber components and thus identify them [17]. In our case (FEI-QUMTA 200SEM) was

\section{Results}

SEM pictures of examined warped linen are illustrated in, fig. (6-a, b), it showing the linen fibers identified from different parts of the object. The used for investigating small samples taken to show the quality of the fibers as well as their damage aspects. Moreover, the type of dye in the colored weft was analyzed with UV analysis, in our case Perkin Elmer Lambda 900 was performed for this purpose.

fibers are extremely damaged with longitudinal splitting characterized, broken and presence of dirt on the fiber, fig. (6-c, d). UV results proved that the 
UV spectrum for that dye converges with the UV Turmeric spectrum, fig. (7-a). The type of adhesive that the piece has been pasted with it on a free acid paper at the excavation site was analyzed, where the resin material was extracted
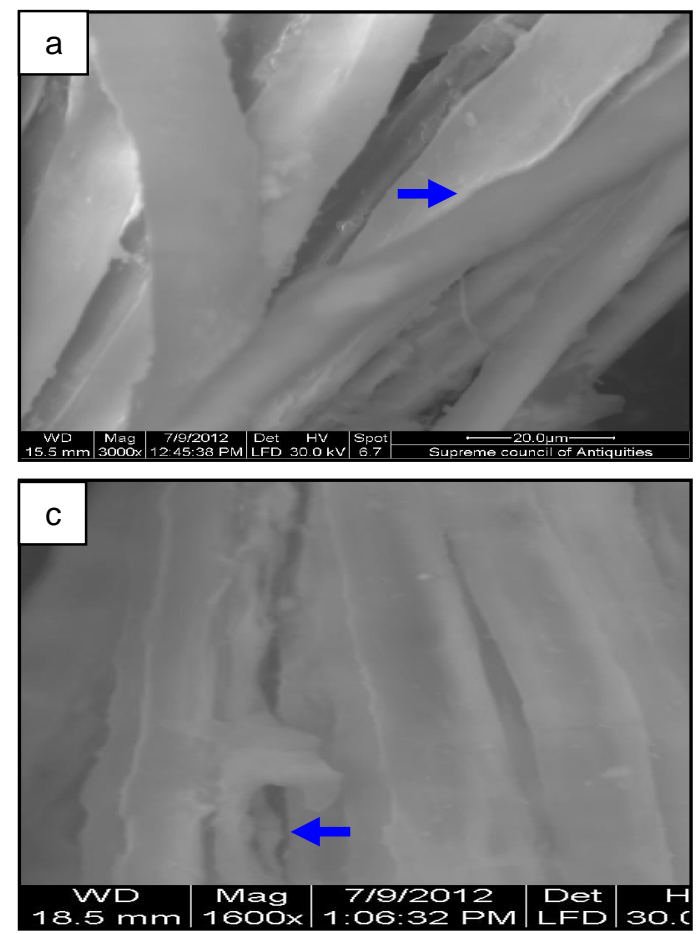

Figure (6) $\underline{\mathbf{a}}$ The warp threads are Linen, $\underline{\mathbf{b}}$ the weft threads are Linen, $\underline{\mathbf{c}}$ the dirt on the fiber, $\underline{\mathbf{d}}$ longitudinal splitting
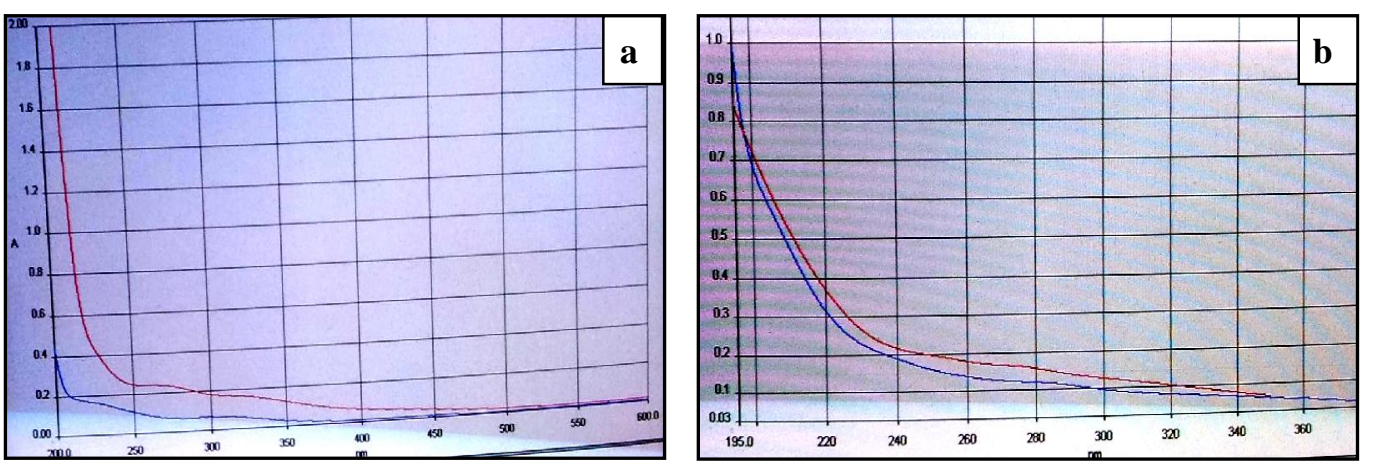

Figure (7) UV analysis showed that $\underline{\mathbf{a}}$ the writing dye is Turmeric, $\underline{\mathbf{b}}$ the adhesive is Arabic gum

\section{Treatment Procedure}

\subsection{Wetting process}

Due to the severe dry edges of the piece that lead to broken it, the dye testing with a drop of water was firstly made. It proved that they are very weak, therefore wetting processes have been conducted by using the water and alcohol (far from the dye) to recover its

of processor paper and analyzed, the result that the UV spectrum of that material converges with the UV spectrum for sugary substance likely that Arabic gum, fig. (7-b).
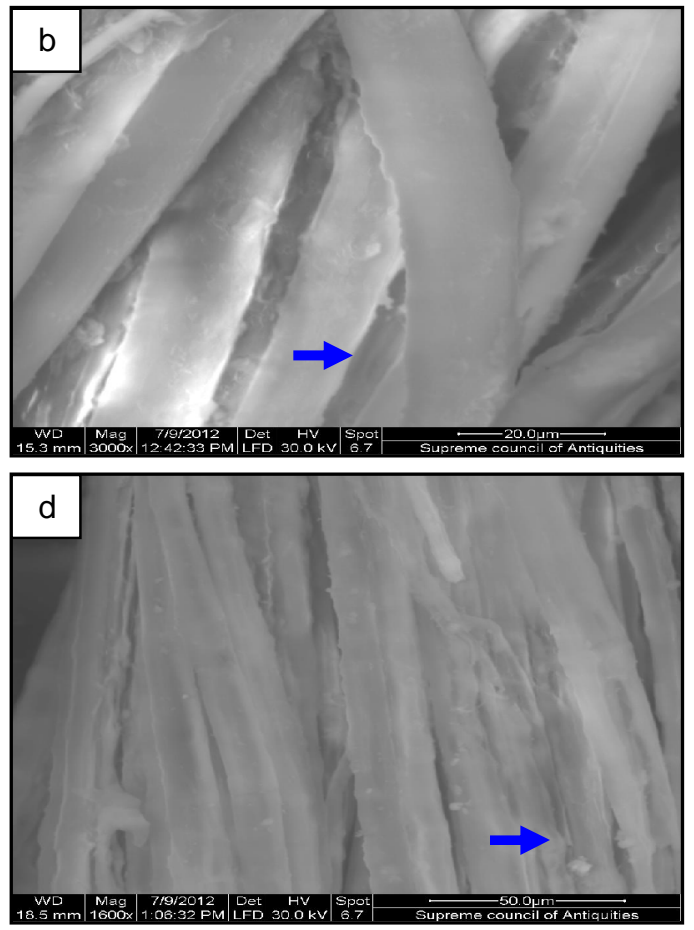

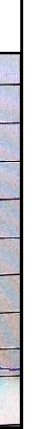

\section{.}




\subsection{Cleaning of the object}

Due to the fiber and dye weakness, dirties accumulated on the piece wasn't cleaned for avoiding the

\subsection{Preparation of wooden frame and textile support}

Blue textile was used (1/1 Plain Weave). Its surface was cleaned using hot water with a few drops of detergent solution (Synperonic N) to remove any element of dust which may exist on the surface, then the textile was rinsed with distilled water for several times to ensure that its disposal of any detergent, as well as to ensure that there is no

\subsection{Temporary fixation}

The piece was temporary fixed on the textile support by using needle work, precisely using thin needle with blue cotton yarn. The piece was put on the textile support with taking into account putting the piece correctly in the middle. In the beginning, the piece was fixed by worked longitudinal, straight and parallel lines and each line length $7 \mathrm{~cm}$ damage increase. So final support process was conducted and was divided into the following stages:

future shrinkage for it and then was dried with iron. The textile size is $35 \times 45$ $\mathrm{cm}$ to tighten it on the wooden frame which was chosen with good quality of wood with size $(30 \times 40 \mathrm{~cm})$. The textile was pulled on a wooden frame by using pins with the province to keep its warps and wefts on a right direction.

and far from the next line to it a distance of about $5 \mathrm{~cm}$, first start the work in the lines of the first row and after completed it comes second row so that mediates the distance between the first lines row then comes the third row as the first alternately until fixed was completed with also fixed the weak places of the piece, as shown in, fig. (8).

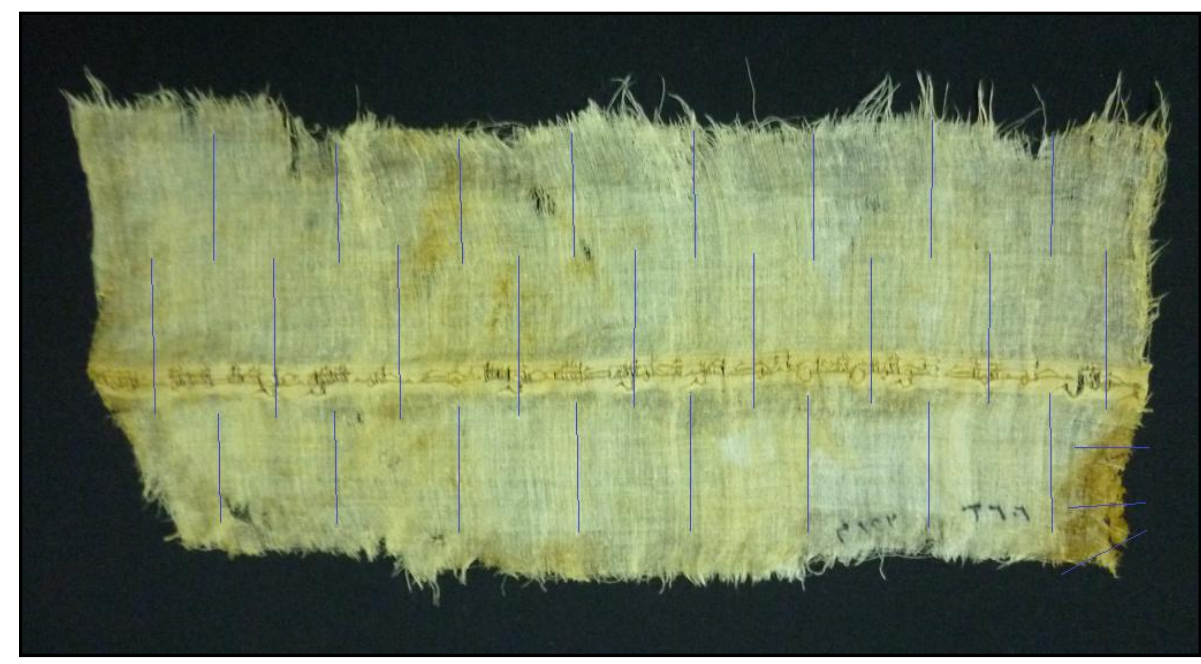

Figure (8) The piece fixed temporarily on the textile support

\subsection{Permanent supporting}

After completion of the temporary fixing, tacking stitches were used with a very fine needle and fine silk thread to fix the writing part. In the beginning of the final stage, the edges of the object all around were attached by sewing with a small stitch technique (blanket stitch) and afterwards the edges of the missing and vulnerable parts were attached by small stitches.
The couching stitches were also used to fix some places in the piece. The embroidery thread was brought through the material, laid in the desired place on the face of the material, and carried through to the back again. From the back side, couching stitches were taken over the thread on the face to keep it in place [18] [19]. 


\subsection{Prepare for the museum display}

After completing the object fixing, it was displayed in a suitable manner according to the museum requirements by using the foam frame because of its good characteristics against the moisture and biological deterioration, in addition to its lightness and easily moving. This procedure was achieved according to the following steps: The $\mathbf{1}^{\text {st }}$ step, a piece of foam has been cut with size $18 \times 35.5 \mathrm{~cm}$ leaving about $5 \mathrm{~cm}$ from each side. The $2^{\text {nd }}$ one, a piece of foam has been introduced inside the wooden frame from the back so that the archaeological textile mediates it. The $\mathbf{3}^{\text {rd }}$ step, wooden frame

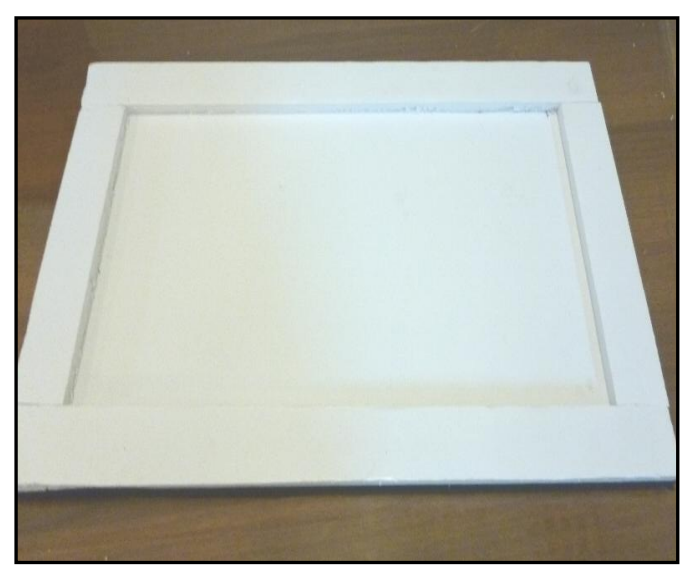

Figure (9) a Foam frame which prepared to the museum display, $\underline{\mathbf{b}}$ Final view for the archaeological piece

\section{Discussion}

This practical study included treatment and conservation of an archaeological textile dates back to the Abbasid period as there are writings in dark yellow dye. The textile structure of the pieces is plain $1 / 1$, but in the written units the piece has been weaved with the technique of weft-face textile with technical of systematic extending plain weave from warp 2/2. The object suffers from fiber damage especially at the edges and terminal fringes. It was supported by needle work on a blue textile. Analyses by Using (SEM) shown that the fibers are made of linen. The object surface is very weak and brittle. UV analysis showed that the writing dye is turmeric and showed that has been turned so that the foam to the top and under it the textile support then the archaeological piece on the prepared glass. The $4^{\text {th }}$ step, the textile support has been cut with larger sizes about $5 \mathrm{~cm}$ from each direction from over wooden frame (which excluded). $\mathbf{5}^{\text {th }}$ step, the edges of the textile support has been adhered From behind with polyvinyl acetate. Finally, two sheets of foam have been cut with sizes $4 \times 35.5 \mathrm{~cm}$, and two sheets have been cut with sizes $4 \times 10 \mathrm{~cm}$ to paste it with polyvinyl acetate on the clear textile support as shown in, fig. (9$a, b)$.

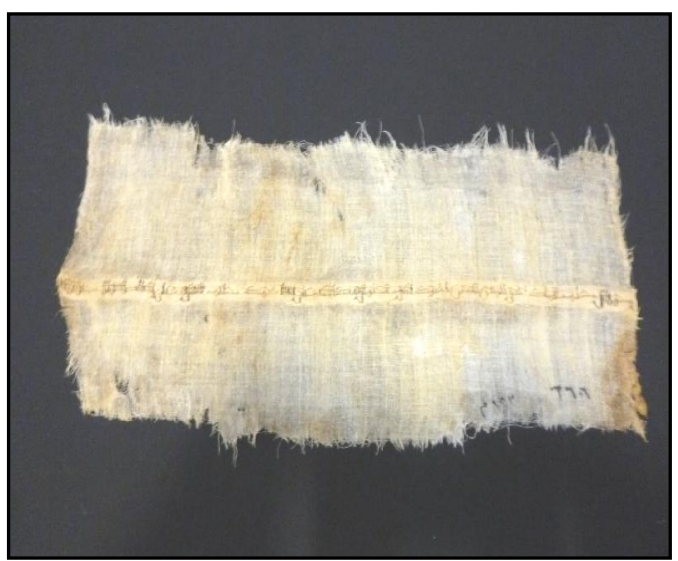

type of adhesive that the piece has been pasted with it on a free acid paper at the excavation site for sugary substance likely that Arabic gum. A treatment was initiated to wetting processes which have been done far from the dye place. It succeeded in the achievement the purpose of it because it helped to remove the piece far from a free acid paper and put it on a blotting paper preparing to support it on a textile support. As well as its participant to get rid of the glue. It helped also to recover the piece to its moisture content the dye testing was applied before the wetting processes it is tested recorded with a drop of water. It was found that the dyes were very weak. There was one 
type of dirt that could not be removed due to the weak of fiber, and the weakness of dye and in order not to increase the damage. The piece has been supported on a blue textile support to appear it by using needle work. Finally, the piece has been prepared to museum display by using foam sheet as a lightly material.

\section{Conclusion}

The study confirms that it is necessary to conserve textile objects in the museum. Conservation processes improved the appearance of the textile due to improved physical and mechanical properties of the objects which will lengthen their survival Also conservation aims to slow down the rate of the further deterioration of textile artifacts as much as possible, and thus to insure that these collections are available for future generations.

\section{References}

1. Vanden Berghe, I., (2012). Towards an early warning system for oxidative degradation of protein fibers in historical tapestries by means of calibrated amino acid analysis, Journal of Archaeological Science, Vol. 39 (5), pp: 1349-1359.

2. Dalmas, F., (2006). Viscoelastic behavior and electrical properties of flexible nano-fiber filled polymer nano-composites. Influence of processing conditions, Composites science and technology, Vol. 67 (5), pp: 829-839.

3. Vicini, S., (2004). Thermal analysis and characterization of cellulose oxidized with sodium methaperiodate, Chemical Acta, Vol. 418 (1-2), pp: 123-130.

4. Down, J., (1996). Predicting the future: Accelerated aging at CCI, Conservation information database, CCI Library Publications, http://www.cciicc.gc.ca - 2/8/2011

5. Bresee, R., (1986). General effects of aging on textiles, JAIC, Vol. 25 (1), pp: $39-48$

6. Feller, R., (1994). Accelerated aging photochemical and thermal aspects, The Getty Conservation Institute, USA.

7. Orlofsky, P., (1993). The role of connoisseurship in determining the textile conservators' treatment options, JAIC, Vol. 32 (2), pp: 109-118.

8. Degano, I., (2011). Historical and archaeological textiles: An insight on degradation products of wool and silk yarns, Journal of Chromatography A, Vol. 1218 (34), pp. 5837-5847.
9. Burgess, H., (1990). The development of a research approach to the scientific study of cellulosic and ligneous materials, JAIC, Vol. 29 (2), pp: 133 152.

10. Belli, R., (2005). Laser cleaning of ancient textiles, Applied Surface Science, Vol. 247 (1-4), pp 369-372.

11. Appelbaum, B., (1987). Criteria for treatment: reversibility, JAIC, Vol. 26, (2), pp: 65-73.

12. Abdel-Kareem, O., (2004). The longterm effect of selected conservation materials used in the treatment of museum artifacts on some properties of textiles, Journal of polymer degradation and stability, Vol. 87, (1), pp. 121-130.

13. Abdel-Kareem, O., (2009). Treatment, conservation and restoration of the Bedouin dyed textiles in the museum of Jordanian heritage, MAA, Vol.10, (1), pp: $25-36$

14. Ahmed, H., (2011). Strategy for preservation of Ptolemaic wrapped mummy's linen in Tuna El-Gebel excavation, Egypt, IJCS, Vol. 2, (3), pp: 155-164.

15. El-Homossani, M., (1988). Early compound weave structures in theory and practice, http://ulita.leeds.ac.uk - 4/9/2012

16. Maarof, M., (2002). Treatment and conservation one of tapestry pieces at the museum of faculty of arts in Sohag, in: Radwan, A \& ElKahlawy, M., (eds.) the $5^{\text {th }}$ Conference for the association of the Arab archaeologists, Cairo, pp: 1181 $-1194$ 
17. D’Orazio, L., (2000). Nature, origin and technology of natural fibers of textile artifacts recovered in the ancient cities around Vesuvius, Journal of Archaeological Science, Vol. 27 (9), pp: 745-754.

18. Perjes, J., (2001). Conservation textiles: Studies in honour of Agnes Timar-
Balazsy, ICCROM, Conservation Studies 7, Rome, Italy.

19. Batigne, R., (1953). The significance and technical analysis of ancient textiles as historical documents, in Proceedings of American Philosophical Society, Vol. 97 (6) pp: 670-680. 